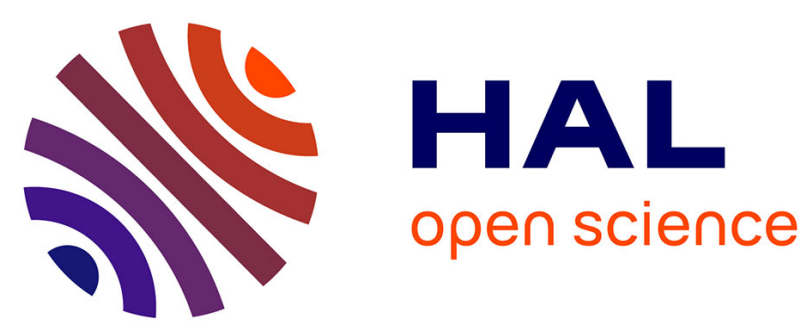

\title{
Multiscale modelling of transport in clays from the molecular to the sample scale
}

Benjamin Rotenberg, Virginie Marry, Mathieu Salanne, Marie Jardat, Pierre Turq

\section{- To cite this version:}

Benjamin Rotenberg, Virginie Marry, Mathieu Salanne, Marie Jardat, Pierre Turq. Multiscale modelling of transport in clays from the molecular to the sample scale. Comptes Rendus Géoscience, 2014, 346 (11-12), pp.298-306. 10.1016/j.crte.2014.07.002 . hal-01491237

\section{HAL Id: hal-01491237 https: / hal.sorbonne-universite.fr/hal-01491237}

Submitted on 13 Nov 2018

HAL is a multi-disciplinary open access archive for the deposit and dissemination of scientific research documents, whether they are published or not. The documents may come from teaching and research institutions in France or abroad, or from public or private research centers.
L'archive ouverte pluridisciplinaire HAL, est destinée au dépôt et à la diffusion de documents scientifiques de niveau recherche, publiés ou non, émanant des établissements d'enseignement et de recherche français ou étrangers, des laboratoires publics ou privés. 


\title{
Multiscale modelling of transport in clays, from the molecular to the sample scale
}

\author{
Benjamin Rotenberg $^{\mathrm{a}, \mathrm{b}, *}$, Virginie Marry ${ }^{\mathrm{a}, \mathrm{b}}$, Mathieu Salanne $^{\mathrm{a}, \mathrm{b}}$, Marie Jardat ${ }^{\mathrm{a}, \mathrm{b}}$, Pierre \\ Turq ${ }^{\mathrm{a}, \mathrm{b}}$ \\ ${ }^{a}$ Sorbonne Universités, UPMC Univ. Paris 06, UMR 8234 PHENIX, 75005 Paris, France \\ ${ }^{b}$ CNRS, UMR 8234 PHENIX, 75005 Paris, France
}

\begin{abstract}
We report some recent applications of multiscale modelling to the transport of ions, water and $\mathrm{CO}_{2}$ in clays. On the one hand, simulations on different scales allow to investigate the physico-chemical processes underlying the geochemical and transport behaviour of these fluids in the interparticle pores and at the surface of clay minerals. We discuss more specifically the insights gained from molecular simulations on the acidity of surface edge sites, ion exchange and the behaviour of clay interlayers in contact with a $\mathrm{CO}_{2}$ reservoir. On the other hand, upscaling the descriptions from the molecular level to the macroscopic scale without forgetting the fundamental role of interfaces on the mesoscopic scale provides a means to capture complex phenomena such as electrokinetic couplings. We illustrate the complementarity of molecular dynamics, lattice-based mesoscopic simulations and Pore Network Models to address this issue.
\end{abstract}

Keywords: Clay minerals, multiscale simulation, acidity, ion exchange, sorption, electrokinetic effects

\section{Introduction}

Understanding the transport of water, ions, gas or oil through clay barriers is essential in the contexts of hydrology, petroleum and gas reservoir engineering, as well as the geological disposal of radioactive waste (ANDRA, 2005: Bradbury and Baeyens, 2003) or $\mathrm{CO}_{2}$ sequestration (Gaus, 2010, DePaolo and Cole, 2013). Clay rocks display a complex multiscale structure, from the regular stacking of aluminosilicate lamellae on the microscopic scale to their disordered assembly into particles on mesoscopic scales $\left(10^{-9}-10^{-6} \mathrm{~nm}\right)$ with corresponding interlayer and interparticle porosities, up to the macroscopic assembly of clays with other minerals (e.g. carbonates or quartz). To this hierarchy of length scales corresponds a variety of physico-chemical phenomena occuring over times spanning several orders of magnitude, many of them associated with the structural charge of the mineral surface: chemical reactivity of surface sites, electrostatic interactions between the surface and ions in the interstitial solution, specific ion effects, wetting, swelling, electrokinetic couplings, etc. The electromagnetic signature of materials, in response to applied electromagnetic or acoustic waves, is at the basis of many logging tools and of seismo-electric exploration (see e.g. (Pride, 1994)).

\footnotetext{
${ }^{*}$ Corresponding author

Email address: benjamin.rotenberg@upmc.fr (Benjamin Rotenberg)
} 
From the modelling point of view, this challenge set by multiple length and time scales can only be addressed within the framework of a multiscale strategy. On the one hand, this means adopting various complementary descriptions of the same system to capture different types of complexity. The reorganization of electrons around nuclei during chemical reactions requires using quantum descriptions, but their computational cost limits their use to a few hundred of atoms (Boek and Sprik, 2003; Suter et al. 2008; Liu et al., 2013). Molecular simulations allow to accurately describe clay layers and interlayers as well as the interface between clay particles and solutions over a few nm (Boek et al. . 1995; Sposito et al., 1999; Marry et al., 2002, Hensen and Smit, 2002; Greathouse and Cygan, 2006, Rotenberg et al., 2010a; Ferrage et al., 2011; Michot et al., 2012). Mesoscocopic simulations are then needed to model phenomena in pores with sizes in the range 10-100 nm (Stukan et al., 2010, Boek and Venturoli, 2010, Rotenberg et al. 2010b). On the other hand, one should make the link between the various levels of description, exploiting more accurate models to calibrate coarser ones retaining the relevant information on larger scales. This "bottom-up" strategy includes for example using ab initio calculations to parametrize force fields (Cygan et al., 2004), or molecular simulation to derive simple kinetic models (Rotenberg et al., 2007a b; Dufrêche et al., 2010, Carof et al., 2014). Even though all the references cited above are applications to clay minerals, this strategy is of course very general and has been successful in many other contexts.

In the present work, we review some recent theoretical and numerical developments in our group, using molecular and mesoscale simulations to address a number of issues related to the transport of ions, water and other fluids in clays. In section 2, we first illustrate the interest of various simulation techniques to gain insight into geochemistry problems: ab initio Molecular Dynamics (MD) to predict the acidity of clay edge sites, classical MD to understand the thermodynamics of ion exchange, and Grand-Canonical Monte Carlo (GCMC) to investigate the interaction of clay interlayers with $\mathrm{CO}_{2}$ reservoirs. In section 3 we then show the interest of a multiscale simulation strategy to describe the transport of water and ions in clays, including electrokinetic couplings, from the molecular to the macroscopic sample scale, using a combination of molecular simulation, lattice-based mesoscopic simulation (Lattice Boltzmann Electrokinetics) and Pore Network Models.

\section{Geochemistry: insights from simulation on the molecular scale}

In order to predict the transport and retention of mobile species in complex, interfacial materials such as clays, one first needs to understand the underlying microscopic mechanisms. Here we examine three examples of such processes for which molecular simulation proved very useful in complementing experimental approaches.

\subsection{Acidity of clay edges}

Lateral surfaces of clay particles may provide sorption sites contributing significantly to the retention of heavy metal cations. This sorption depends largely on the protonation state of the various edge sites, which is controlled by their $\mathrm{p} K_{a}$ and the $\mathrm{pH}$ of the solution (Tournassat et al. 2013). Figure 1 illustrates silanol $\mathrm{SiOH}$ and aluminol $\mathrm{AlOH}$ and $\mathrm{AlOH}_{2}$ sites on the (010) surface of a dioctahedral TOT clay. Titration experiments only provide a global measure of the surface state and do not allow to assess the state of individual sites (which however matters for cation sorption) (Bourg et al., 2007). In practice, an efficient strategy consists in introducing a priori or experimental structural information in semi-empirical models such as MUSIC (Hiemstra et al., 1996; Machesky et al., 2008) in order to reproduce the titration curve (Tournassat et al., 2004).

In this context, molecular simulation is an attractive alternative for evaluating the acidity of individual sites. The $\mathrm{p} K_{a}$ is related to the reaction free energy for the transfer of the surface proton to a water molecule, e.g. for a silanol group:

$$
-\mathrm{SiOH}+\mathrm{H}_{2} \mathrm{O}_{a q} \rightarrow-\mathrm{SiO}^{-}+\mathrm{H}_{3} \mathrm{O}_{a q}^{+} .
$$

This involves the breaking and formation of chemical bonds so that DFT-based simulations are necessary (even though reactive force fields are now available, they remain less accurate, in particular for proton transfer reactions). Since the relaxation of bond lengths on edge surfaces plays an important role on the acid-base properties (White and Zelazny, 1988), it has first been proposed to introduce refined structures from ab initio simulations into bond-valence based models, both in terms of bond lengths (Bickmore et al., 2003) and of solvation structure (coordination numbers and bond lengths) (Bickmore et al., 2006; Machesky et al., 2008). Using ab initio molecular dynamics (AIMD), Churakov studied water confined between edges of pyrophyllite and evidenced transient proton exchange between 


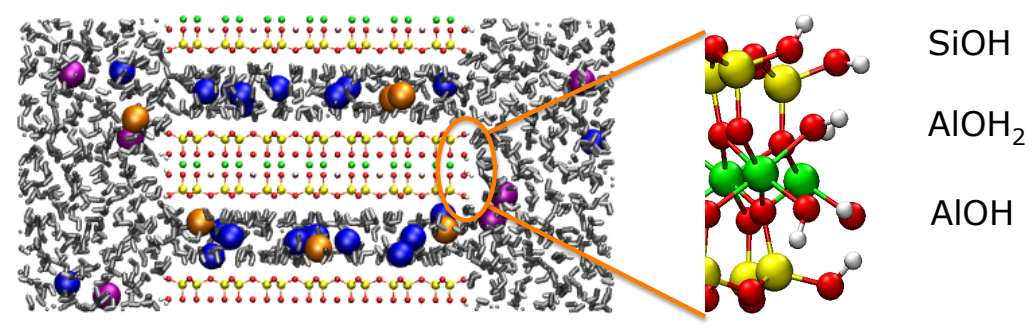

Figure 1. Lateral surfaces of clay particles display edge sites arising from the reaction of broken $\mathrm{Si}-\mathrm{O}$ and $\mathrm{Al}-\mathrm{O}$ bonds with water molecules. The resulting groups, here silanol and aluminol on the (010) surface of a dioctahedral TOT clay such as montmorillonite, may protonate or deprotonate depending on the $\mathrm{pH}$ of the interstitial solution. The $\mathrm{p} K_{a}$ of each site can be determined separately from ab initio simulations, whereas experimental titration data can only provide global information. Color code: yellow $=\mathrm{Si}$, green $=\mathrm{Al}$, red $=\mathrm{O}$, white $=\mathrm{H}$. In the left part water molecules are in grey and the spheres represent $\mathrm{Na}^{+}$(blue), $\mathrm{Cs}^{+}$(orange) and $\mathrm{Cl}^{-}$(pink) ions.

surface groups mediated by surface water molecules (Churakov, 2007). He also proposed a first attempt to provide an acidity scale of the surface groups from their deprotonation energy in vacuum (Churakov, 2006), which neglects entropic contributions and the solvent reorganization after deprotonation.

By combining AIMD with thermodynamic integration (Sulpizi and Sprik, 2010), we computed the free energy for the deprotonation reaction (1) of $\mathrm{SiOH}, \mathrm{AlOH}$ and $\mathrm{AlOH}_{2}$ sites on the (010) surface of pyrophyllite (Tazi et al., 2012). SiOH is slightly more acidic than $\mathrm{AlOH}_{2}$, with $\mathrm{p} K_{a}$ values close to 7 for both sites, whereas $\mathrm{AlOH}$ does not deprotonate in water $\left(\mathrm{p} K_{a} \sim 22\right)$. In addition, the reorganization free energy, arising from bond length relaxation and solvent reorganization after deprotonation, is an important contribution to the overall free energy and cannot be neglected. For example, the strong stabilization of $\mathrm{SiO}^{-}$after deprotonation is explained by the arrival of two water molecules donating H-bonds. Following the same strategy, Liu et al. recently extended this study to assess the role of $\mathrm{Al}^{\mathrm{III}} \rightarrow \mathrm{Mg}^{\mathrm{II}}$ substitutions near edges in montmorillonite (Liu et al. 2013). It was found that $\mathrm{Mg}$ substitutions increase the $\mathrm{p} K_{a}$ of the neighbouring $\mathrm{SiOH}$ group by $2-3 \mathrm{p} K_{a}$ units. Overall, these studies suggest that the sites mainly responsible for heavy cation sorption should be the deprotonated $\mathrm{SiOH}$ and $\mathrm{AlOH}_{2}$ sites.

\subsection{Ion exchange}

One of the most important processes governing cation retention by clays is cation exchange, between ions in solution and interlayer counterions, as illustrated in Figure 2. The exchange of interlayer $\mathrm{Na}^{+}$counterions by $\mathrm{Cs}^{+}$in solution is thermodynamically favorable $\left(\Delta_{r} G<0\right)$ and exothermic $\left(\Delta_{r} H<0\right)$. It was generally admitted that this was the result of favorable interactions (of various origins) between the $\mathrm{Cs}^{+}$cation and the clay surface. This point of view was challenged by Teppen and Miller (Teppen and Miller. 2006), who computed by molecular simulation the free energy associated with the replacement of $\mathrm{Na}^{+}$by larger alkaline cations, and found that this contribution is in fact unfavorable for the exchange.

The following thermodynamic cycle separates the contribution of ion replacement in both the clay interlayer (with a fixed number of water molecules per cation) and the aqueous phase ( $a q$ subscript):

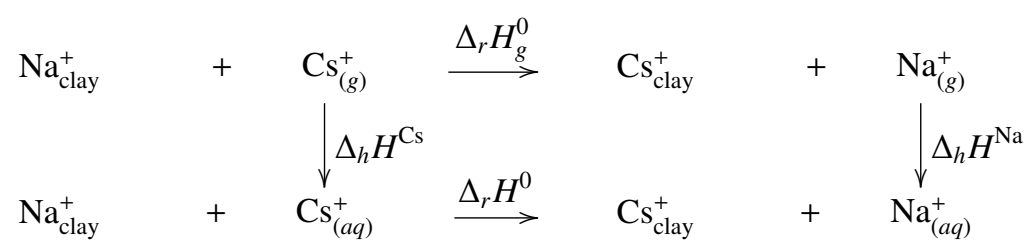

This cycle involves the exchange reaction with ions in the gas phase ( $g$ subscript), where there are no interactions, used as a reference state. The associated thermodynamic quantities are the hydration enthalpy of both cations $\Delta_{h} H^{\mathrm{Na}}$ and $\Delta_{h} H^{\mathrm{Cs}}$, the standard ionic exchange reaction with the gas phase $\Delta_{r} H_{g}^{0}$ and that with the aqueous phase $\Delta_{r} H^{0}$. 


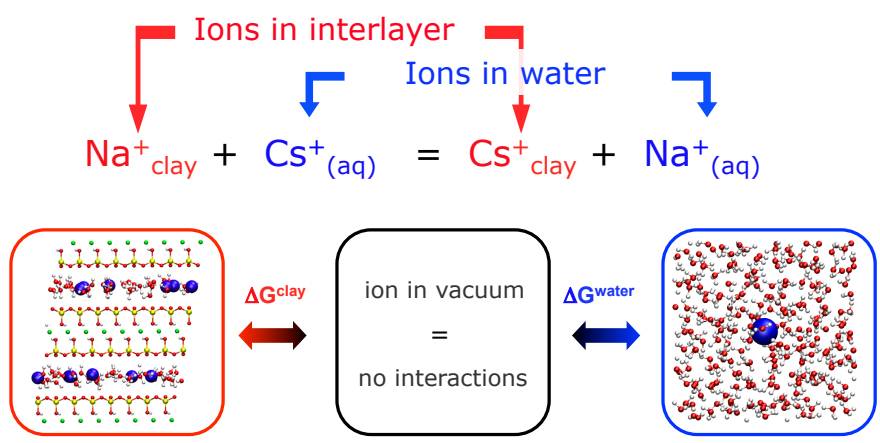

Figure 2. Cation exchange reaction between the clay interlayer and an aqueous solution. The contributions of both phases to the overall enthalpy and Gibbs free energy can be analyzed separately in molecular simulations.

Using molecular simulations, we showed that replacing $\mathrm{Na}^{+}$by $\mathrm{Cs}^{+}$in the interlayer is in fact an endothermic process $\left(\Delta_{r} H_{g}^{0}>0\right)$, and that the overall exchange is exothermic $\left(\Delta_{r} H^{0}<0\right)$ only because of the hydration enthalpy difference $\Delta \Delta_{h} H=\Delta_{h} H^{\mathrm{Cs}}-\Delta_{h} H^{\mathrm{Na}} \sim 133 \mathrm{~kJ} \cdot \mathrm{mol}^{-1}$ associated with the replacement of $\mathrm{Cs}^{+}$by $\mathrm{Na}^{+}$in the aqueous phase. This conclusion, as well as the evolution of $\Delta_{r} H^{0}$ with water content, were confirmed by microcalorimetry experiments (Rotenberg et al. 2009). Similarly, for the exchange of $\mathrm{Cs}^{+}$traces in Na-montmorillonite we found that the contribution of the clay phase to the exchange is positive and large $\left(\Delta_{r} G \sim+120 \mathrm{~kJ}_{r} \cdot \mathrm{mol}^{-1}\right)$ and that the overall exchange is thermodynamically favorable only due to the replacement of $\mathrm{Cs}^{+}$by $\mathrm{Na}^{+}$in the aqueous phase.

While the thermodynamics of ion exchange can be studied by considering only the initial and final bulk states, understanding the exchange process requires the explicit account of the interface between the interlayer and the aqueous solution via the lateral surface. Using the setup illustrated in the left part of Figure 1, we found that for Namontmorillonite in the bilayer state water and cations can exchange via the edges with no or small activation barriers, whereas anions are excluded from the interlayer (we estimated the associated free energy cost to $\sim 23 \mathrm{~kJ} . \mathrm{mol}^{-1}$ in that case) (Rotenberg et al. 2007c). For larger distances between the surfaces and larger salt concentrations, this anion exclusion becomes less dramatic and some salt may enter into the nanopores. In order to assess systematically the effect of salt concentration and interlayer distance on the ratio between the "internal" and "external" salt concentration (Donnan effect), we introduced a continuous solvent model, parametrized on molecular simulation (Jardat et al., 2009). The correlations between ions modulate the salt exclusion and two regimes were found: At low reservoir concentration, the Coulomb attraction between ions increases the amount of salt in the interlayer space compared to the Poisson-Boltzmann predictions, while at high concentration excluded volume (due to the finite size of the ions) dominate.

\subsection{Contact with a $\mathrm{CO}_{2}$ reservoir}

Several options are currently considered for the geological sequestration of $\mathrm{CO}_{2}$. One of them is to inject supercritical $\mathrm{CO}_{2}$ in saline aquifers: This fluid would partly be dissolved and trapped physically (microbubbles) or chemically (carbonate precipitation) in such porous formations, but some would eventually rise by buoyancy as a separate phase until it encounters an impermeable caprock. It is then important to predict the evolution of the often clay-rich caprock due to the contact with the reservoir (Gaus, 2010). In this context too, molecular simulation gives access to the microscopic mechanisms at play (Hamm et al. 2013). Among the many possible scenarios, we have considered the possibility of clay interlayer swelling or dehydration. In the latter case, this would lead to the shrinkage of clay particles, resulting in fractures increasing the permeability of the caprock.

To that end, we performed Grand-Canonical Monte Carlo simulations of sodium montmorillonite clays in contact with $\mathrm{H}_{2} \mathrm{O}$ and $\mathrm{CO}_{2}$ reservoirs. The number of molecules in the interlayer fluctuates as a result of matter exchange with the reservoirs which set the chemical potentials of the fluid (see Figure 3). For given thermodynamic conditions in the reservoirs we monitor the interlayer composition and pressure for each interlayer distance, from which we determine the swelling free energy. The thermodynamically stable states then correspond to the minima of this free energy. 

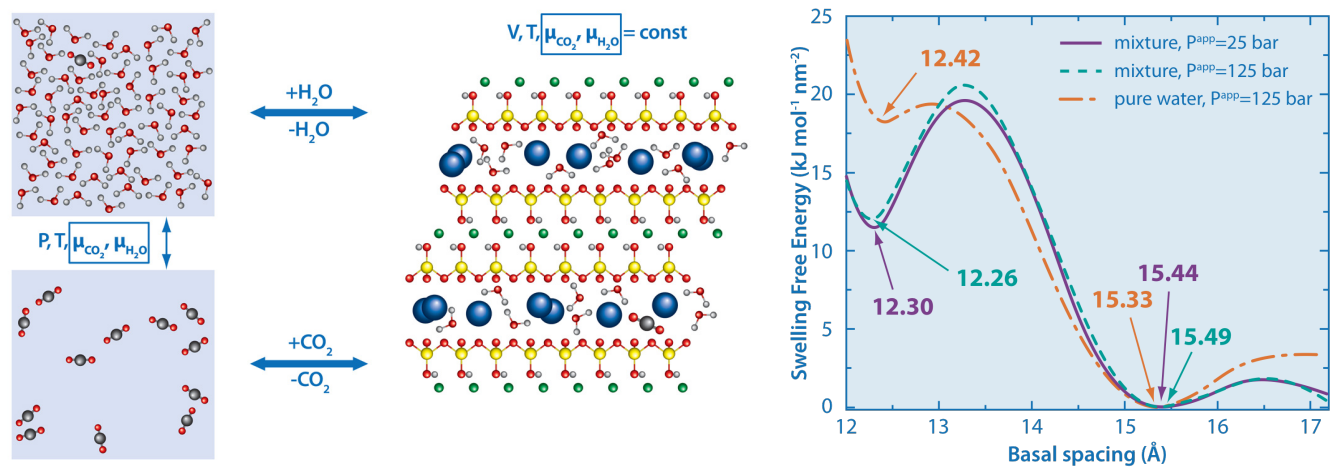

Figure 3. Grand-Canonical Monte Carlo simulations $\mathrm{H}_{2} \mathrm{O}$ and $\mathrm{CO}_{2}$ molecules are exchanged between the interlayer of a sodium montmorillonite clay and the reservoirs, which set the chemical potentials of both species. While in the reservoirs, under the considered pressure and temperature, a $\mathrm{H}_{2} \mathrm{O}$-rich phase and a $\mathrm{CO}_{2}$-rich phase coexist, one finds only intercalation of $\mathrm{CO}_{2}$ molecules inside the hydrated interlayers which correspond to the minima of the swelling free energy as a function of the basal spacing (right). See Ref. (Botan et al. 2010) for more information.

For the considered thermodynamic conditions $(T=348 \mathrm{~K}$ and $P=125 \mathrm{bar})$ we found that from the initial state with $\mathrm{H}_{2} \mathrm{O}$ only, the contact with the $\mathrm{CO}_{2}$ reservoir does not change the location of these minima (in other words, we should not expect swelling or shrinkage) (Botan et al. 2010). We further investigated the structure and dynamics of $\mathrm{CO}_{2}$ intercalated in montmorillonite interlayers, demonstrating in particular the slowing down of all interlayer species in the presence of $\mathrm{CO}_{2}$. Experiments have confirmed the presence of intercalated $\mathrm{CO}_{2}$ in hydrated montmorillonite interlayers (Giesting et al. 2012a b) and recent molecular dynamics studies provided further insights into the interlayer properties (Cygan et al. 2012; Myshakin et al. 2013).

\section{Transport, from the molecular to the sample scale}

Modelling the transport of fluids in charged multiscale materials such as clay is a challenge because it is limited by the smallest pores, with sizes in the 1-100 $\mathrm{nm}$ range, where interfacial effects such as wetting or electrokinetic couplings play a dominant role. Under confinement down to the $\mathrm{nm}$ scale one should also expect the departure from continous hydrodynamics (Bocquet and Charlaix, 2010). Once continuous transport equations on the pore scale are known (e.g. Stokes), they can be upscaled to the corresponding ones (e.g. Darcy's law) on the macroscopic sample scale, using numerical or analytical homogenization approaches. Here we illustrate how simulations on three different scales allow to assess the relevance of continuous models, to solve the electrokinetic equations on the pore scale and to upscale the electrokinetic couplings in complex heterogenous materials.

\subsection{Hydrodynamics in clay nanopores}

Using MD simulations, we investigated the applicability of continuous hydrodynamics (Navier-Stokes equation) in clay nanopores, with pore widths ranging from 2 to $9 \mathrm{~nm}$ (Botan et al.,2011). Figure4 4illustrates the simulated setup for sodium montmorillonite clay surfaces separated by $3.5 \mathrm{~nm}$. The solvent density displays strong oscillations near the surface, reflecting the layering of water over 2-3 molecular diameters. Depending on their size and valency, cations may form either inner-sphere or outer-sphere complexes at the surface (Greathouse and Cygan, 2006, Marry et al., 2008). In the absence of subsitutions in the mineral layers (hence of counterions) the basal surfaces are hydrophobic, even though the presence of hydroxyl groups may render the competition between water-water and water-surface interactions more delicate, as in the case of talc (Rotenberg et al. 2011).

Once the pore composition is known for given thermodynamic conditions (e.g. from prior Grand-Canonical Monte Carlo simulations, see Section 2.3, it is possible to simulate the effect of a pressure gradient by applying a force along the surface on the fluid. The steady-state velocity profile is then measured and compared to the prediction of continuous hydrodynamics (parabolic Poiseuille flow profile in this case). For sufficiently large pores, this profile is 


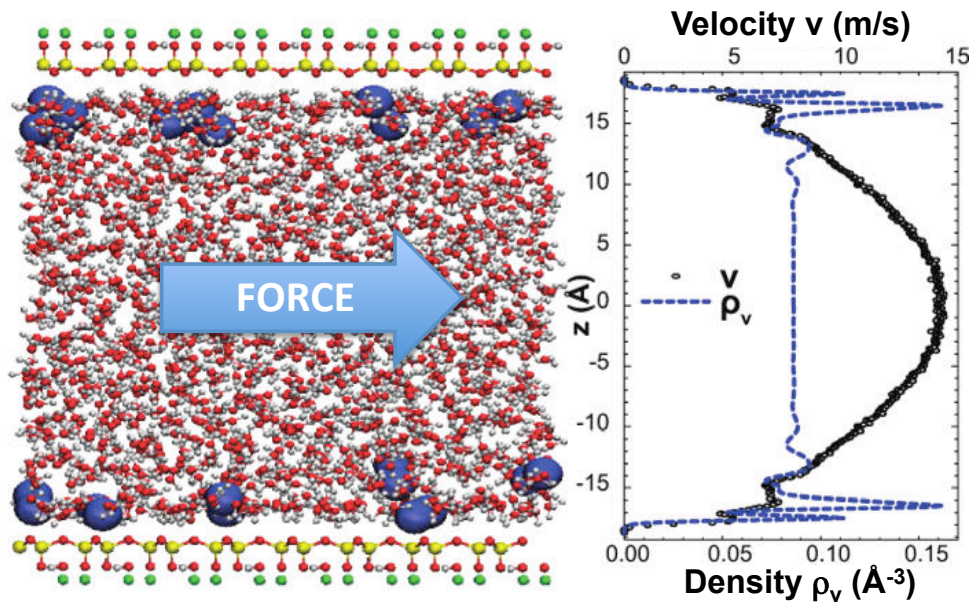

Figure 4. Non-equilibrium molecular dynamics Under the effect of an applied force, mimicking a pressure gradient, the steady-state flow profile (black symbols) may deviate from the prediction of continuous hydrodynamics, in particular due to the layering of the solvent density (blue dashed line) at the surfaces. When the distance between sodium montorillonite clay surfaces exceeds $3 \mathrm{~nm}$, the velocity profile far from the surface is reasonably well described by a Poiseuille flow, however only if a slip boundary condition is introduced, with a slip length derived from molecular simulations. Reprinted with permission from Botan et al., The Journal of Physics C 114 (35) (2010) 1496214969. Copyright 2011 American Chemical Society.

parabolic near the center of the pore, and the effective viscosity corresponding to the measured curvature is comparable to the bulk viscosity. However, deviations are observed near the surface, as an expected result of layering. More importantly, the profile far from the surface is reproduced by the Navier-Stokes equation only if a slip boundary condition is used. This in turn allows the determination of the corresponding slip length from molecular simulation. The latter is very small $(\sim 2.1 \AA)$ but its effects on the overall flow through the pore can be large for pore widths of a few $\mathrm{nm}$.

More recently, we followed the same strategy to investigate the electro-osmotic flow induced by an electric field along the clay surfaces (Botan et al. 2013, Rotenberg and Pagonabarraga, 2013). Here again, in order to reproduce the molecular simulation results with continuous equations it is essential to introduce appropriate slip boundary conditions at the clay/solution interface, as had been previously observed in equilibrium MD (Dufrêche et al. 2005). This study also confirmed the limitations of the Poisson-Boltzmann equation for the description of the ionic profiles and of the resulting electric force profile in the presence of the applied electric field.

\subsection{Electrokinetic couplings on the pore scale}

While molecular simulation provides the most accurate description of the clay/solution interface, its computational cost prevents its use for large systems which are necessary to capture the effect of the complex pore structure over 10100 s of nanometers. To that end, one relies on simpler descriptions. The standard model for electrokinetic couplings on the pore scale is thus the so-called Poisson-Nernst-Planck (PNP) model, which couples (i) the Nernst-Planck equation for the transport of ions under the combined effects of advection, diffusion and migration due to the local electric field, (ii) Poisson's equation to determine the electrostatic potential from the electric charge distribution and (iii) Navier-Stokes (NS) equations for the evolution of the fluid under local pressure and electric potential gradients, taking into account viscous dissipation.

These equations can be solved numerically using finite element or volume methods. For example, Adler and co-workers used this direct numerical resolution in various complex systems (random packings, reconstructed and fractured porous media) (Coelho et al., 1996; Marino et al., 2001), demonstrating in particular a universal electrokinetic behaviour if appropriate rescaled quantities are introduced (Gupta et al. 2006, 2008). Recently, alternative methods have been proposed to simulate electrokinetic effects starting from a more fundamental description of the fluid than the PNP and NS equation (Pagonabarraga et al. 2010). For example, Capuani et al. proposed a hybrid 
lattice based approach (Lattice Boltzmann Electrokinetics, LBE) to capture the coupling of hydrodynamic flow with ion transport and the simulation of electrokinetic effects in colloidal suspensions (Capuani et al., 2004, Pagonabarraga et al., 2005). We applied this method to porous media and extended it to charged liquid-liquid interfaces (Rotenberg et al., 2008, 2010b) as well as to capture the effect of salt concentration gradients (osmosis) (Obliger et al., 2013).

(a)

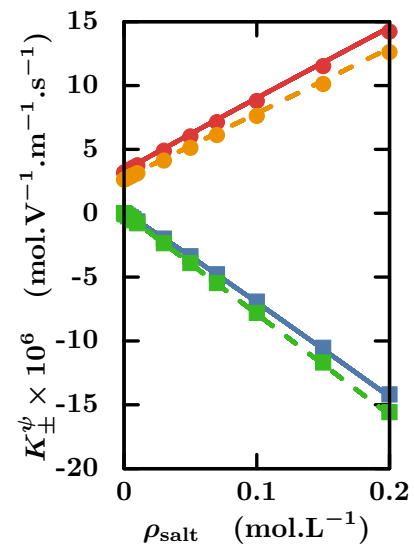

(b)

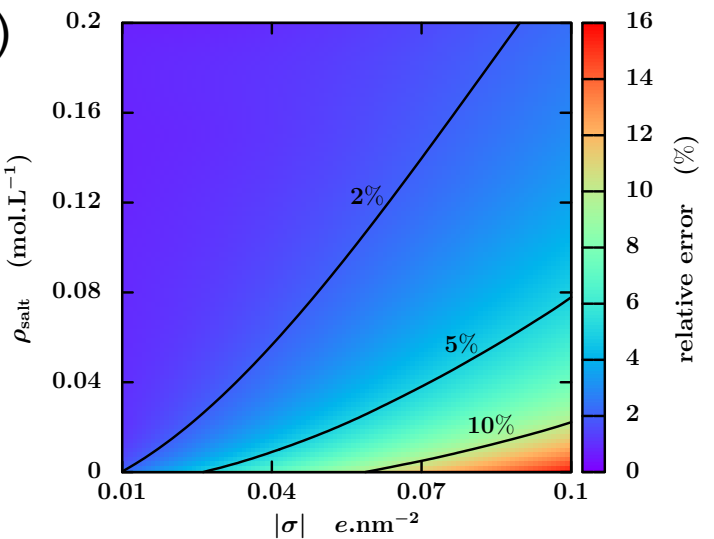

Figure 5. Lattice Boltzmann Electrokinetics (LBE) (a) Coefficients of the transfer matrix describing the cation (•) and anion ( $\square$ ) fluxes under an applied potential $(\psi)$ gradient, in a cylindrical channel of radius $5 \mathrm{~nm}$ and surface charge density $\sigma=-0.08 e \mathrm{~nm}^{-2}$, as a function of salt concentration $\rho_{\text {salt }}$. The total electrical permeability $K_{ \pm}^{\psi}=K_{ \pm}^{e o}+K_{ \pm}^{N E}$ (red and blue solid lines for cations and anions, respectively) as well as the Nernst-Einstein $K_{ \pm}^{N E}$ (orange and green dashed lines for cations and anions, respectively) are indicated. LBE simulations (symbols) are compared to the analytical results obtained with the linearized Poisson-Boltzmann (PB) equation (lines). (b) Relative error on the electro-osmotic permeability for cations $K_{+}^{e o}$ due to the linearization of the PB equation, compared to the non-linear one (as determined by LBE simulations), as a function of the surface charge density $\sigma$ and of the salt concentration $\rho_{\text {salt }}$. Reprinted with permission from Obliger et al., Physical Review E 88 (1) (2013) 013019. Copyright 2013 by the American Physical Society.

As an example of application of LBE in the perspective of a numerical homogenization strategy, Figure 5 a reports the coefficients of the transfer matrix describing cation and anion fluxes under an applied potential gradient, in a cylindrical channel of fixed radius and surface charge density, as a function of salt concentration. These fluxes include both the direct effect of the electric field on the ions (Nernst-Einstein contribution, proportional to the ion concentrations and their mobility) and the electro-osmotic contribution (advection by the fluid flow). The former drives cations and anions in opposite directions, while the latter, in the present case of a negative surface charge, increases the cation flux and mitigates that of anions. Such numerical simulations also allow to assess the validity of approximate analytical theories obtained by linearizing the Poisson-Boltzmann equation, which can be used in models on larger scales (see Section 3.3). Figure $5 \mathrm{p}$ reports the relative error of this approximate solution compared to the non-linear one for a fixed channel radius, as a function of the surface charge density and of the salt concentration.

\subsection{Electrokinetics: from the pore scale to the sample scale}

Once transport properties are known on the pore scale, it is sometimes possible to upscale rigorously from a mathematical point of view the PNP equations using the homogenization approach (Allaire et al., 2010), even introducing mechanical couplings (Moyne and Murad, 2006a b) or extensions to capture non-ideality of the electrolyte (Allaire et al., 2014). While very general in principle, most studies of electrokinetic couplings consider simple geometries (slits or cylinders) with dimensions and surface charge densities estimated from the macroscopic properties of the real system. Direct numerical simulation on complex porous networks is typically limited, due to the high computational cost, to system sizes in the $10-100 \mathrm{~s} \mathrm{~nm}$ range. In order to investigate electrokinetic couplings on larger scales, including the effect of the heterogeneity of the material, we have recently proposed a simplified description based on the Pore Network Model (PNM). Such a model, originally developed by Fatt (Fatt 1956) to predict multiphase flow properties in porous media, describes the porosity as a network of pores connected by channels, as illustrated 
in Figure 6a. It has been extensively used and extended by petrophysicists in various situations, such as capillarity and multiphase flow through porous media (Blunt, 2001; van Dijke and Sorbie, 2002, Békri et al. 2005), or mineral dissolution and precipitation in the context of $\mathrm{CO}_{2}$ sequestration (Algive et al., 2010).
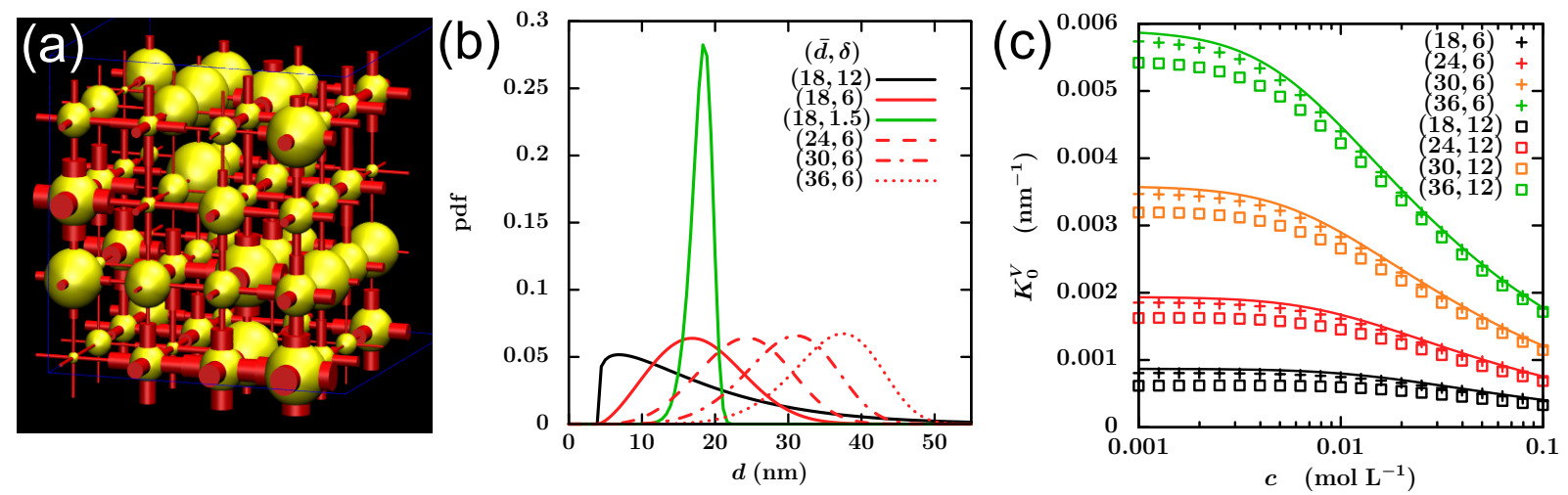

Figure 6. Pore Network Model (a) Transport properties on the network scale are determined by the transport matrix of each channel (red) connecting pores (yellow). (b) Channel diameter distribution, here of the Weibull form, for several average $(\bar{d})$ and standard deviation $(\delta)$ in nm. (c) Evolution of the electro-osmotic coupling coefficient $K_{0}^{V}$ describing the solvent flow under an applied electric field, as a function salt concentration in the reservoir $c$, for various channel size distributions $(\bar{d}, \delta)$. The surface charge density is fixed to $-0.05 e \mathrm{~nm}^{-2}$ and lines indicate the result for a network composed of identical channels $(\delta=0)$. Panels (b) and (c) reprinted with permission from Obliger et al., Physical Review E 89 (4) (2014) 043013. Copyright 2014 by the American Physical Society.

In a nutshell, the PNM approach amounts to solving a set of conservation equations on the nodes of the network (in analogy with Kirchhoff's law for a network of resistors), on the basis of local fluxes through the channels connecting the nodes, under the effect of external macroscopic gradients. In the case of electrokinetic couplings, this requires introducing a transport matrix for each channel relating the solvent, cation and anion fluxes to the pressure, concentration and potential gradients across the channel. In addition, the matrix for each channel depends not only on its diameter and surface charge density, but also on the salt concentration in the pores at both ends, via the Donnan equilibrium (see Section 2.2) so that the problem to be solved numerically is a non-linear one (Obliger et al., 2014).

From the knowledge of the transfer matrix on the channel scale, either analytically using approximations or numerically e.g. from LBE simulations as described in Section 3.2, and of the channel diameter distribution, one can finally determine the macroscopic transfer matrix on the network scale. Examples of such distributions are shown on Figure $6 p$, together with the effect of the sample heterogeneity on the macroscopic electro-osmotic coupling coefficient. In general, the coefficients of this matrix qualitatively behave as their microscopic counterpart for a channel with the average diameter. However, the combined effects of electrokinetic couplings on the local scale and of heterogeneity result in a decrease of the overall transport coefficients. This decrease is more pronounced for large surface charge densities and low salt concentrations. In addition, for a given average diameter, more heterogeneous samples result in stronger effects, due to the presence of smaller pores. With this new numerical tool at hand, we are currently examining the case of the Callovo-Oxfordian argilite in the context of the geological disposal of radioactive waste in France.

\section{Conclusion}

We have illustrated here some recent applications of multiscale modelling to the transport of ions, water and $\mathrm{CO}_{2}$ in clays. On the one hand, simulations on different scales allow to address the physico-chemical processes underlying the geochemical and transport behaviour of these fluids in the interparticle pores and at the surface of clay minerals. On the other hand, upscaling the descriptions from the molecular level to the macroscopic scale without forgetting the fundamental role of interfaces on the mesoscopic scale provides a means to capture complex phenomena such 
as electrokinetic couplings. This multiscale approach, followed in our group mainly in the case of transport, is also very fruitful for the description of other properties of clays, such as mechanical ones (Carrier et al., 2014, Brisard and Dormieux, 2010). Extensions to more complex fluids would also provide an efficient route for the modelling of hydrocarbons in oil and gas shales.

In the future, one should also benefit from recent numerical (Tyagi et al., 2013) and experimental (Levitz, 2007. Brisard et al. 2012) developments for the generation of realistic numerical samples for the description of real materials. As a recent example, Robinet et al. recently simulated the diffusion of solutes in 3D-images of a CallovoOxfordian clay-rich rock obtained by SEM and micro-CT experiments to investigate the effect of mineral distribution (Robinet et al. 2012). Multiscale experiments using NMR also provide an ideal tool to investigate the multiscale dynamics of mobile species in such complex materials (Porion et al., 2013).

\section{Acknowledgements}

The authors are grateful to many colleagues and students who have contributed to this work over the last ten years, in particular Alexandru Boţan, Sami Tazi, Amaël Obliger, Magali Duvail, Antoine Carof, Natalie Malikova, JeanFrançois Dufrêche, Rodolphe Vuilleumier, Jean-Pierre Hansen, Daniel Coelho, Benoît Noetinger and Samir Bekri.

\section{References}

Algive, L., Békri, S., Vizika, O., 2010. Pore-network modeling dedicated to the determination of the petrophysical-property changes in the presence of reactive fluid. SPE Journal 15.

Allaire, G., Brizzi, R., Dufrêche, J.F., Mikelic, A., Piatnitski, A., 2014. Role of non-ideality for the ion transport in porous media: derivation of the macroscopic equations using upscaling. submitted to Physica D ArXiv preprint, 1309.3679.

Allaire, G., Mikelic, A., Piatnitski, A., 2010. Homogenization of the linearized ionic transport equations in rigid periodic porous media. Journal of Mathematical Physics 51, 123103.

ANDRA, 2005. Évaluation de la faisabilité du stockage géologique en formation argileuse. Dossier 2005 Argile : Synthèse, Châtenay-Malabry, France.

Békri, S., Laroche, C., Vizika, O., 2005. Pore network models to calculate transport and electrical properties of single or dual-porosity rocks, in: SCA, p. 2005.

Bickmore, B.R., Rosso, K.M., Nagy, K.L., Cygan, R.T., Tadanier, C.J., 2003. Ab initio determination of edge surface structures for dioctahedral 2:1 phyllosilicates: Implications for acid-base reactivity. Clays and Clay Minerals 51, 359-371.

Bickmore, B.R., Rosso, K.M., Tadanier, C.J., Bylaska, E.J., Doud, D., 2006. Bond-valence methods for p $K_{a}$ prediction. II. Bond-valence, electrostatic, molecular geometry, and solvation effects. Geochimica et Cosmochimica Acta 70, 4057-4071.

Blunt, M.J., 2001. Flow in porous media pore-network models and multiphase flow. Current Opinion in Colloid \& Interface Science 6, $197-207$.

Bocquet, L., Charlaix, E., 2010. Nanofluidics, from bulk to interfaces. Chemical Society Reviews 39, $1073-1095$.

Boek, E.S., Coveney, P.V., Skipper, N.T., 1995. Monte carlo molecular modeling studies of hydrated Li-, Na-, and K-smectites: Understanding the role of potassium as a clay swelling inhibitor. Journal of the American Chemical Society 117, 12608-12617.

Boek, E.S., Sprik, M., 2003. Ab initio molecular dynamics study of the hydration of a sodium smectite clay. The Journal of Physical Chemistry B 107, 3251-3256.

Boek, E.S., Venturoli, M., 2010. Lattice-Boltzmann studies of fluid flow in porous media with realistic rock geometries. Computers \& Mathematics with Applications 59, 2305-2314.

Botan, A., Marry, V., Rotenberg, B., Turq, P., Noetinger, B., 2013. How electrostatics influences hydrodynamic boundary conditions: Poiseuille and electro-osmostic flows in clay nanopores. The Journal of Physical Chemistry C 117, 978-985.

Botan, A., Rotenberg, B., Marry, V., Turq, P., Noetinger, B., 2010. Carbon dioxide in montmorillonite clay hydrates: Thermodynamics, structure, and transport from molecular simulation. The Journal of Physical Chemistry C 114, 14962-14969.

Botan, A., Rotenberg, B., Marry, V., Turq, P., Noetinger, B., 2011. Hydrodynamics in clay nanopores. The Journal of Physical Chemistry C 115, 16109-16115.

Bourg, I.C., Sposito, G., Bourg, A.C.M., 2007. Modeling the acid-base surface chemistry of montmorillonite. Journal of Colloid and Interface Science 312, 297-310.

Bradbury, M., Baeyens, B., 2003. Near Field Sorption Data Bases for Compacted MX-80 Bentonite for Performance Assessment of a High-Level Radioactive Waste Repository in Opalinus Clay Host Rock. Paul Scherrer Institut, Switzerland.

Brisard, S., Chae, R.S., Bihannic, I., Michot, L., Guttmann, P., Thieme, J., Schneider, G., Monteiro, P.J.M., Levitz, P., 2012. Morphological quantification of hierarchical geomaterials by X-ray nano-CT bridges the gap from nano to micro length scales. American Mineralogist 97 , 480-483.

Brisard, S., Dormieux, L., 2010. FFT-based methods for the mechanics of composites: A general variational framework. Computational Materials Science 49, 663-671.

Capuani, F., Pagonabarraga, I., Frenkel, D., 2004. Discrete solution of the electrokinetic equations. The Journal of Chemical Physics $121,973-986$.

Carof, A., Marry, V., Salanne, M., Hansen, J.P., Turq, P., Rotenberg, B., 2014. Coarse graining the dynamics of nano-confined solutes: the case of ions in clays. Molecular Simulation 40, 237-244. 
Carrier, B., Vandamme, M., Pellenq, R.J.M., Van Damme, H., 2014. Elastic properties of swelling clay particles at finite temperature upon hydration. The Journal of Physical Chemistry C (doi:10.1021/jp412160e)

Churakov, S.V., 2006. Ab initio study of sorption on pyrophyllite: Structure and acidity of the edge sites. The Journal of Physical Chemistry B $110,4135-4146$.

Churakov, S.V., 2007. Structure and dynamics of the water films confined between edges of pyrophyllite: A first principle study. Geochimica et Cosmochimica Acta 71, 1130-1144.

Coelho, D., Shapiro, M., Thovert, J.F., Adler, P.M., 1996. Electroosmotic phenomena in porous media. Journal of colloid and interface science 181, 169-190.

Cygan, R.T., Liang, J.J., Kalinichev, A.G., 2004. Molecular models of hydroxide, oxyhydroxide, and clay phases and the development of a general force field. The Journal of Physical Chemistry B 108, 1255-1266.

Cygan, R.T., Romanov, V.N., Myshakin, E.M., 2012. Molecular simulation of carbon dioxide capture by montmorillonite using an accurate and flexible force field. The Journal of Physical Chemistry C 116, 13079-13091.

DePaolo, D.J., Cole, D.R., 2013. Geochemistry of geologic carbon sequestration: An overview. Reviews in Mineralogy and Geochemistry 77, $1-14$.

van Dijke, M.I.J., Sorbie, K.S., 2002. Pore-scale network model for three-phase flow in mixed-wet porous media. Physical Review E 66, 046302.

Dufrêche, J.F., Marry, V., Malikova, N., Turq, P., 2005. Molecular hydrodynamics for electro-osmosis in clays: from Kubo to Smoluchowski. Journal of molecular liquids $118,145-153$.

Dufrêche, J.F., Rotenberg, B., Marry, V., Turq, P., 2010. Bridging molecular and continuous descriptions: the case of dynamics in clays. Anais da Academia Brasileira de Ciencias 82, 61-68.

Fatt, I., 1956. The network model of porous media, part I: Capillary characteristics. Petrol Trans AIME, 144-159.

Ferrage, E., Sakharov, B.A., Michot, L.J., Delville, A., Bauer, A., Lanson, B., Grangeon, S., Frapper, G., Jimenez-Ruiz, M., Cuello, G.J., 2011. Hydration properties and interlayer organization of water and ions in synthetic na-smectite with tetrahedral layer charge. Part 2. Toward a precise coupling between molecular simulations and diffraction data. The Journal of Physical Chemistry C 115, 1867-1881.

Gaus, I., 2010. Role and impact of $\mathrm{CO}_{2}$-rock interactions during $\mathrm{CO}_{2}$ storage in sedimentary rocks. International Journal of Greenhouse Gas Control 4, 73-89.

Giesting, P., Guggenheim, S., Koster van Groos, A.F., Busch, A., 2012a. Interaction of carbon dioxide with Na-exchanged montmorillonite at pressures to 640 bars: Implications for $\mathrm{CO}_{2}$ sequestration. International Journal of Greenhouse Gas Control 8, 73-81.

Giesting, P., Guggenheim, S., Koster van Groos, A.F., Busch, A., 2012b. X-ray diffraction study of K- and Ca-exchanged montmorillonites in $\mathrm{CO}_{2}$ atmospheres. Environmental Science \& Technology 46, 5623-5630.

Greathouse, J.A., Cygan, R.T., 2006. Water structure and aqueous uranyl(VI) adsorption equilibria onto external surfaces of beidellite, montmorillonite, and pyrophyllite: Results from molecular simulations. Environmental Science \& Technology 40, 3865-3871.

Gupta, A., Coelho, D., Adler, P., 2008. Universal electro-osmosis formulae for porous media. Journal of colloid and interface science 319, 549-554.

Gupta, A.K., Coelho, D., Adler, P.M., 2006. Electroosmosis in porous solids for high zeta potentials. Journal of colloid and interface science 303, 593-603.

Hamm, L.M., Bourg, I.C., Wallace, A.F., Rotenberg, B., 2013. Molecular simulation of $\mathrm{CO}_{2}$ - and $\mathrm{CO}_{3}$-Brine-Mineral systems. Reviews in Mineralogy and Geochemistry 77, 189-228.

Hensen, E.J.M., Smit, B., 2002. Why clays swell. The Journal of Physical Chemistry B 106, 12664-12667.

Hiemstra, T., Venema, P., Riemsdijk, W.H.V., 1996. Intrinsic proton affinity of reactive surface groups of metal (hydr)oxides: The bond valence principle. Journal of Colloid and Interface Science 184, 680-692.

Jardat, M., Dufrêche, J.F., Marry, V., Rotenberg, B., Turq, P., 2009. Salt exclusion in charged porous media: a coarse-graining strategy in the case of montmorillonite clays. Physical Chemistry Chemical Physics 11, 2023-2033.

Levitz, P., 2007. Toolbox for 3D imaging and modeling of porous media: Relationship with transport properties. Cement and Concrete Research $37,351-359$.

Liu, X., Lu, X., Sprik, M., Cheng, J., Meijer, E.J., Wang, R., 2013. Acidity of edge surface sites of montmorillonite and kaolinite. Geochimica et Cosmochimica Acta 117, 180-190.

Machesky, M.L., Predota, M., Wesolowski, D.J., Vlcek, L., Cummings, P.T., Rosenqvist, J., Ridley, M.K., Kubicki, J.D., Bandura, A.V., Kumar, N., Sofo, J.O., 2008. Surface protonation at the rutile (110) interface: Explicit incorporation of solvation structure within the refined MUSIC model framework. Langmuir 24, 12331-12339.

Marino, S., Shapiro, M., Adler, P., 2001. Coupled transports in heterogeneous media. Journal of Colloid and Interface Science 243, $391-419$.

Marry, V., Rotenberg, B., Turq, P., 2008. Structure and dynamics of water at a clay surface from molecular dynamics simulation. Physical Chemistry Chemical Physics 10, 4802-4813.

Marry, V., Turq, P., Cartailler, T., Levesque, D., 2002. Microscopic simulation of structure and dynamics of water and counterions in a monohydrated montmorillonite. The Journal of Chemical Physics 117, 3454.

Michot, L.J., Ferrage, E., Jimnez-Ruiz, M., Boehm, M., Delville, A., 2012. Anisotropic features of water and ion dynamics in synthetic Na- and Ca-smectites with tetrahedral layer charge. A combined quasi-elastic neutron-scattering and molecular dynamics simulations study. The Journal of Physical Chemistry C 116, 16619-16633.

Moyne, C., Murad, M.A., 2006a. A two-scale model for coupled electro-chemo-mechanical phenomena and Onsager's reciprocity relations in expansive clays: I homogenization analysis. Transport in Porous Media 62, 333-380.

Moyne, C., Murad, M.A., 2006b. A two-scale model for coupled electro-chemo-mechanical phenomena and Onsager's reciprocity relations in expansive clays: II computational validation. Transport in Porous Media 63, 13-56.

Myshakin, E.M., Saidi, W.A., Romanov, V.N., Cygan, R.T., Jordan, K.D., 2013. Molecular dynamics simulations of carbon dioxide intercalation in hydrated Na-montmorillonite. The Journal of Physical Chemistry C 117, 11028-11039.

Obliger, A., Duvail, M., Jardat, M., Coelho, D., Békri, S., Rotenberg, B., 2013. Numerical homogenization of electrokinetic equations in porous media using lattice-Boltzmann simulations. Physical Review E 88, 013019.

Obliger, A., Jardat, M., Coelho, D., Békri, S., Rotenberg, B., 2014. Pore network model of electrokinetic transport through charged porous media. 
Physical Review E 89, 043013.

Pagonabarraga, I., Capuani, F., Frenkel, D., 2005. Mesoscopic lattice modeling of electrokinetic phenomena. Computer physics communications 169, 192-196.

Pagonabarraga, I., Rotenberg, B., Frenkel, D., 2010. Recent advances in the modelling and simulation of electrokinetic effects: bridging the gap between atomistic and macroscopic descriptions. Physical Chemistry Chemical Physics 12, 9566-9580.

Porion, P., Faugère, A.M., Delville, A., 2013. Multiscale water dynamics within dense clay sediments probed by ${ }^{2} \mathrm{H}$ multiquantum NMR relaxometry and two-time stimulated echo NMR spectroscopy. The Journal of Physical Chemistry C 117, 26119-26134.

Pride, S., 1994. Governing equations for the coupled electromagnetics and acoustics of porous media. Physical Review B 50, 15678-15696.

Robinet, J.C., Sardini, P., Coelho, D., Parneix, J.C., Prêt, D., Sammartino, S., Boller, E., Altmann, S., 2012. Effects of mineral distribution at mesoscopic scale on solute diffusion in a clay-rich rock: Example of the Callovo-Oxfordian mudstone (Bure, France). Water Resources Research 48, W05554.

Rotenberg, B., Marry, V., Dufrêche, J.F., Giffaut, E., Turq, P., 2007a. A multiscale approach to ion diffusion in clays: Building a two-state diffusion-reaction scheme from microscopic dynamics. Journal of Colloid and Interface Science 309, 289-295.

Rotenberg, B., Marry, V., Dufrêche, J.F., Malikova, N., Giffaut, E., Turq, P., 2007b. Modelling water and ion diffusion in clays: a multiscale approach. Comptes Rendus Chimie 10, 1108-1116.

Rotenberg, B., Marry, V., Malikova, N., Turq, P., 2010a. Molecular simulation of aqueous solutions at clay surfaces. Journal of Physics: Condensed Matter 22, 284114.

Rotenberg, B., Marry, V., Vuilleumier, R., Malikova, N., Simon, C., Turq, P., 2007c. Water and ions in clays: Unraveling the interlayer/micropore exchange using molecular dynamics. Geochimica et Cosmochimica Acta 71, 5089-5101.

Rotenberg, B., Morel, J.P., Marry, V., Turq, P., Morel-Desrosiers, N., 2009. On the driving force of cation exchange in clays: Insights from combined microcalorimetry experiments and molecular simulation. Geochimica et Cosmochimica Acta 73, 4034-4044.

Rotenberg, B., Pagonabarraga, I., 2013. Electrokinetics: insights from simulation on the microscopic scale. Molecular Physics 111, 827-842.

Rotenberg, B., Pagonabarraga, I., Frenkel, D., 2008. Dispersion of charged tracers in charged porous media. EPL (Europhysics Letters) 83, 34004.

Rotenberg, B., Pagonabarraga, I., Frenkel, D., 2010b. Coarse-grained simulations of charge, current and flow in heterogeneous media. Faraday Discussions 144, 223-243.

Rotenberg, B., Patel, A.J., Chandler, D., 2011. Molecular explanation for why talc surfaces can be both hydrophilic and hydrophobic. Journal of the American Chemical Society 133, 20521-20527.

Sposito, G., Skipper, N.T., Sutton, R., Park, S.h., Soper, A.K., Greathouse, J.A., 1999. Surface geochemistry of the clay minerals. Proceedings of the National Academy of Sciences 96, 3358-3364.

Stukan, M.R., Ligneul, P., Crawshaw, J.P., Boek, E.S., 2010. Spontaneous imbibition in nanopores of different roughness and wettability. Langmuir $26,13342-13352$.

Sulpizi, M., Sprik, M., 2010. Acidity constants from DFT-based molecular dynamics simulations. Journal of Physics: Condensed Matter 22, 284116.

Suter, J.L., Boek, E.S., Sprik, M., 2008. Adsorption of a sodium ion on a smectite clay from constrained ab initio molecular dynamics simulations. The Journal of Physical Chemistry C 112, 18832-18839.

Tazi, S., Rotenberg, B., Salanne, M., Sprik, M., Sulpizi, M., 2012. Absolute acidity of clay edge sites from ab-initio simulations. Geochimica et Cosmochimica Acta 94, 1-11.

Teppen, B.J., Miller, D.M., 2006. Hydration energy determines isovalent cation exchange selectivity by clay minerals. Soil Science Society of America Journal 70, 31.

Tournassat, C., Ferrage, E., Poinsignon, C., Charlet, L., 2004. The titration of clay minerals: II. Structure-based model and implications for clay reactivity. Journal of Colloid and Interface Science 273, 234-246.

Tournassat, C., Grangeon, S., Leroy, P., Giffaut, E., 2013. Modeling specific pH dependent sorption of divalent metals on montmorillonite surfaces. A review of pitfalls, recent achievements and current challenges. American Journal of Science 313, 395-451.

Tyagi, M., Gimmi, T., Churakov, S.V., 2013. Multi-scale micro-structure generation strategy for up-scaling transport in clays. Advances in Water Resources 59, 181-195.

White, G.N., Zelazny, L.W., 1988. Analysis and implications of the edge structure of dioctahedral phyllosilicates. Clays and Clay Minerals 36, $141-146$. 